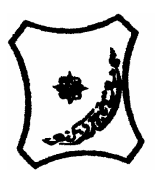

Bayero Journal of Pure and Applied Sciences, 7(2): $36-43$

Received: February 2014

Accepted: July 2014

ISSN $2006-6996$

\title{
FRACTIONATION OF LEAD-ACID BATTERY SOIL AMENDED WITH BIOCHAR
}

\author{
${ }^{a}$ Anegbe, B., ${ }^{b}$ Okuo, J.M., ${ }^{b}$ Ewekay, E.O. and ' ${ }^{b}$ Ogbeifun, D.E. \\ aDepartment of Basic and Industrial Chemistry, Western Delta University, P.M.B. 10, Oghara, Delta State. \\ ${ }^{b}$ Environmental Analytical Research Laboratory, Department of Chemistry, University of Benin, Benin City. \\ Correspondence author: Okuojm@yahoo.com
}

\begin{abstract}
Mobile (bio)available metal concentration in contaminated soils can be minimized through biological immobilization and stabilization methods using a range of organic compounds, such as "biochar." Biochar has a high surface area, highly porous, variable - charge organic material that has the potential to increase soil water holding capacity, surface sorption and base saturation when added to soil. The soil was characterized before and after amending by standard method. The parent soil used for this study was collected from lead-acid battery chargers' workshop. The physico-chemical properties of the soil are: pH=5.0, $0.24 \%$ organic carbon, $32.5 \mathrm{cmol} . \mathrm{kg}^{-1} \mathrm{CEC}$,

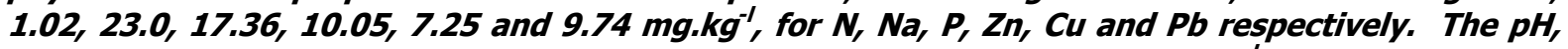

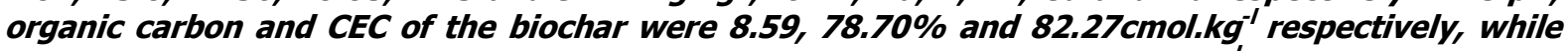
the concentration of heavy metals in the biochar ranged; $0.10-1.20 \mathrm{mg} . \mathrm{kg}^{-1}$. There is a gradual decrease in the concentration of the heavy metals as the concentration of biochar increases from 5 - 20\%. Fractionation result shows that the heavy metals ( $\mathrm{Zn}, \mathrm{Cr}, \mathrm{Cd}, \mathrm{Cu}$ and $\mathrm{Pb})$ were mainly associated with the residual fraction, the mobility factor for the heavy metals was calculated and found to be higher for all metals in the parent soil than the Biochar amended soil. Contamination levels were moderate for $\mathrm{Cd}$ and $\mathrm{Cr}$, considerably for $\mathrm{Pb}, \mathrm{Cu}$ and $\mathrm{Zn}$. The results indicated that long term discharge of these battery chargers' wastes into the environment will cause accumulation of some toxic metals in soils which may lead to elevated levels of these metals in plants.

Keywords: Biochar, Lead-acid Battery, Fractionation and Heavy metals.
\end{abstract}

\section{INTRODUCTION}

The evaluation of heavy metals contamination of soils as a means of monitoring the status of the environment for the good of the ecosystem is crucial. With increased exploitation of natural resources, industrialization and urbanization, most areas of the Niger Delta region of Nigeria are facing an increasing ecological problems arising from the release of pollutants into both the aquatic and terrestrial environments. Heavy metals constitute significant group of these pollutants (Udosen, et al., 2006). While many heavy metals are essential elements at low levels of concentration, they can exert toxic effects at concentrations higher than permitted in the environment. Mobile (bio) available metal concentration in contaminated soils can be minimized through biological immobilization and stabilization methods using a range of organic compounds, such as "biochar", which is a form of environmental black carbon produced using the pyrolysis of C-based biomass (Verheijen et al., 2010). Biochar is produced as a soil amender for agricultural and environmental gain, which distinguishes it from other carbonaceous products such as activated carbon (AC) and charcoal. Application of biochar to soil can help improve soil properties and enhance soil quality by retaining higher moisture, nutrients and microbial activity, therefore increasing crop production (Warnock et al., 2007; Major et al., 2007). Recent attention has been given to biochar as a soil amender because of its potential soil conditioning properties and benefits to physicochemical characteristics. Organic carbon contents of biochar have been reported to be as high as $90 \%$, depending on the source material which encourages experimental application to soils to sequester carbon (Lehmann, 2007a and b). Further potential benefits of adding biochar to soil have also been reported; these include the adsorption of dissolved organic carbon (Pietikainen et al., 2000), increases in soil pH and key soil macro-elements and reductions in trace metals in leachates (Novak et al., 2009). Unlike other soil amendments, biochar's longevity in soil reduces the possibility of heavy metal accumulation associated with repeated applications of other amendments (Joseph et al., 2009), such as sewage sludge. Application of biochar into contaminated or polluted soils can also reduce the bioavailability of heavy metals to plants (Abeh et al., 2007). Therefore, the objectives of this study are: to determine chemical speciation of heavy metals in the soil and to prepare and apply biochar from palm kernel, to lead-acid battery soil.

\section{MATEERIALS AND METHOD}

Soil Sampling, Biochar Preparation

Topsoil $(0-15 \mathrm{~cm})$ samples were collected from lead-acid battery workshops in Benin City. The soil samples were air - dried, pooled and sieve to less than $2 \mathrm{~mm}$. The palm kernel shells used in the preparation of the biochar were obtained from a Palm Oil Mill in Uselu, Benin City. The palm kernel shells were pyrolysed at $500^{\circ} \mathrm{C}$ for 8hrs (Lehmann, 2007a). The char produced was ground and sieved to less than $2 \mathrm{~mm}$. 
The biochar was applied to the soil at four different concentration $(5 \%, 10 \%, 15 \%$ and $20 \%)$, in triplicates, mixed thoroughly and turned over frequently for seven weeks.

pH: Twenty grams of the soil sample was weighed into a $50 \mathrm{~mL}$ beaker and $20 \mathrm{~mL}$ of distilled water was added. The soil/water mixture (ratio 1:1) was allowed to stand for 30 minutes and stirred occasionally with a glass rod. The ele $\mathrm{pH}$ meter was calibrated using buffer 4 and 7 . The electrodes were rinsed and subsequently immersed into the soil/water mixture. The $\mathrm{pH}$ was recorded. (Black, 1965).

Cation Exchange Capacity: Five grams of soil sample was weighed into a $250 \mathrm{~mL}$ polypropylene bottle and $100 \mathrm{~mL}$ of $1 \mathrm{M} \mathrm{NH} \mathrm{N}_{4} \mathrm{OAc}$ solution was added and stoppered. The mixture was shaken for $30 \mathrm{mins}$ in a mechanical shaker (Heldoph) at 200rpm for 30mins. The supernatant was filtered through Whatman No.1 filter paper.

The concentration of $\mathrm{K}^{+}$and $\mathrm{Na}^{+}$in the extract were determined by Flame photometer while $\mathrm{Mg}^{2+}$ and $\mathrm{Ca}^{2+}$ were determined using Atomic Absorption Spectrophotometer (Buck Scientific VGP 210 model). The equipments were calibrated using various concentrations of the metals ranging from 220ppm prepared from analytical grade reagents (Sigma, BDH and Buck Scientific). The summation of the various cations was reported as action exchange capacity (Black, 1965).

Phosphorus: Five grams of the soil was weighed into a polypropylene bottle and $40 \mathrm{~mL}$ of the extracting solution was added and stoppered. The mixture was shaken manually for one minute and filtered with Whatman filter paper No. 1. The clear supernatant was kept for phosphorus determination, (Bray and Kurtz, 1947).

Nitrogen: Finely ground soil $(0.2 \mathrm{~g})$ was weighed into a $100 \mathrm{~mL}$ Kjedahl digestion flask. One tablet of selenium catalyst and $4 \mathrm{~mL}$ of concentrated $\mathrm{H}_{2} \mathrm{SO}_{4}$ were added to the flask and heated on the digester until the mixture became clear. The mixture was cooled until just warm to touch and $10 \mathrm{~mL}$ distilled water was added and the mixture filtered through a Whatman No.1 filter paper into a $100 \mathrm{~mL}$ volumetric flask. The flask was further rinsed with distilled water and the filtrate made up to mark. The concentration of nitrogen in the filtrate was determined by colorimetric method (Vogel's, 2008).

\section{Calculation:}

$$
N(p p m)=\frac{I R \times S R \times C \text { Vextractolum } \times 10^{-6} \times 100 \times c f}{\text { Weighof sampleAliquattaken }}
$$

Where

$$
\begin{array}{lll}
\text { IR } \quad= & \text { Instrument reading } \\
\text { SR }= & \text { Reciprocal of slope obtained from } \\
\text { plot of standards } & \\
\mathrm{CV} \quad= & \text { Color volume } \\
\mathrm{cf} \quad= & \text { Correction factor }
\end{array}
$$

Soil particle size was determine using the hydrometer method (Bouyoucos 1962). Soil organic carbon was determine using the Walkley and Black method (1934), while chemical fractionation and total heavy metals determination was carried out according to Tessier et al., (1979). This involves the separation of metal into five operationally defined fractions: exchangeable (F1), bound to carbonate (F2), bound to Fe-Mn oxide (F3), bound to organic matter (F4) and residual fraction (F5). All glasswares used were soaked and washed with chromic acid. Bulk scientific standard solution was used to calibrate the Atomic Absorption Spectrometer (Pg A500 model). Procedural blank samples were subjected to similar extraction method using the same amount of reagents.

\section{RESULTS AND DISCUSSION}

The results obtained from the physico-chemical analysis of the biochar, parent soil and soil-amended with biochar are shown in Table 1 . Soil pH is the most widely accepted parameter which exerts a controlling influence on the availability of micro-nutrients and heavy metals in the soil to plants (Sanders, 1982; Igwe et al., 2005). Banjoko and Sobulo, (1994) reported that some Nigerian soils especially in the forest and savannah regions are within a $\mathrm{pH}$ range of $5.70-6.50$. This was taken as the normal $\mathrm{pH}$ range for ordinary soils that favour plant and microorganisms. The $\mathrm{pH}$ of the soil from the lead-acid

\begin{tabular}{|c|c|c|c|c|c|c|}
\hline & Biochar & $\begin{array}{c}0 \% \\
\text { Control }\end{array}$ & $\begin{array}{l}5 \% \\
\text { Amendment }\end{array}$ & $\begin{array}{l}10 \% \\
\text { Amendment }\end{array}$ & $\begin{array}{c}15 \% \\
\text { Amendment }\end{array}$ & $\begin{array}{l}20 \% \\
\text { Amendment }\end{array}$ \\
\hline Clay (\%) & - & 11.90 & - & - & - & - \\
\hline Silt (\%) & - & 5.80 & - & - & - & - \\
\hline Sand (\%) & - & 82.30 & - & - & - & - \\
\hline Soil pH & 8.59 & 5.20 & 5.51 & 5.92 & 6.78 & 7.84 \\
\hline C (\%) & 78.70 & 0.24 & 3.96 & 7.97 & 11.73 & 15.95 \\
\hline N (\%) & 0.17 & 1.02 & 1.03 & 1.05 & 1.07 & 1.08 \\
\hline $\mathrm{Na}(\mathrm{mg} / \mathrm{kg})$ & 1200.01 & 23.00 & 58.67 & 134.67 & 230.37 & 255.00 \\
\hline $\mathrm{K}(\mathrm{mg} / \mathrm{kg})$ & 8860 & 117.00 & 728.67 & 1348.67 & 1967.67 & 2578.00 \\
\hline $\mathrm{Ca}(\mathrm{mg} / \mathrm{kg})$ & 5400 & 4300.00 & 4539.67 & 4800.33 & 5104.33 & 5368.33 \\
\hline $\mathrm{Mg}(\mathrm{mg} / \mathrm{kg})$ & 5200 & 1272.00 & 1432.00 & 1630.67 & 1826.67 & 2025.33 \\
\hline $\mathrm{CEC}(\mathrm{cmol} / \mathrm{kg})$ & 82.27 & 32.50 & 36.72 & 41.64 & 46.77 & 51.44 \\
\hline$P(\mathrm{mg} / \mathrm{kg})$ & 5200.96 & 17.36 & 268.20 & 535.90 & 772.30 & 1065.90 \\
\hline
\end{tabular}
battery charger workshop (0\%) was found to be in the range of acidic region (5.18- 5.22) and acidity controls availability, mobility and toxicity of heavy metal ions in the soils.

Table1. Physico-Chemical Properties of Biochar, Soil and the Amended Soil 
There is a gradual increase in soil $\mathrm{pH}$ as biochar application rate increases from $5 \%$ (5.51) to $20 \%$ (7.84) as shown in Table 1. This increase in soil $\mathrm{pH}$ is as a result of the alkaline reaction of biochar used i.e the liming effect of biochar is attributed to ash accreation as ash residues are generally dominated by carbonates of alkali and alkaline earth metals, small amount of heavy metals, phosphates, organic and inorganic nitrogen. In agreement with this, Arocena and Opio (2003), also reported the capacity of ashes to neutralize acidic soil. Another reason for the increase in soil $\mathrm{pH}$ due to application of biochar could be because of high surface area and porous nature of biochar that increases the cation exchange capacity (CEC) of the soil. These favors nutrient availability and crop productivity (Yamato et al., 2006). Application of biochar on soil from leadacid battery charger workshops significantly increased the mean values of soil organic carbon and total nitrogen (Table 1). The highest values of organic carbon and total nitrogen were observed in soils amended with $20 \%$ palm kernel shell biochar (Table 1). The increase in organic carbon and total nitrogen due to addition of biochar could result from the presence of high amount of carbon and nitrogen in the palm kernel shell. The highest values of organic carbon at biochar treated soils indicate the recalcitrance of organic-carbon in biochar. High organic carbon in soils treated with biochar has also been reported by Solomon et al., (2007) and Liang et al., (2006). They also reported higher organic carbon and total nitrogen at the ancient terra preta compared with adjacent soils. The amount of available phosphorous in the parent sample soil was also significantly increased by application of biochar. The observed increase in available phosphorus could be due to the presence of high phosphorous in the palm kernel shell. The increase in soil $\mathrm{pH}$ and CEC, that reduce the activity of iron and aluminium, could also contribute to the highest values of available phosphorus. As soil $\mathrm{pH}$ increases the available phosphorous increases in soils treated with biochar with $20 \%$ having the highest available P. The CEC of the soil sample is low (32.50). CEC is known as a good indicator for evaluating soil fertility, more especially for nutrient retention and thus it prevents cations from leaching into the groundwater. The clay and soil organic matter in the parent soil( $0 \%)$ are quite low, this accounts for the low amount of various metal cation such as $\mathrm{Ca}^{2+} \cdot \mathrm{Na}^{+}, \mathrm{K}^{+}$and $\mathrm{Mg}^{2+}$ in the parent soil sample. These metals are usually retained in the clay or soil organic matter (SOM) by complexation, adsorption and ion-exchange. The application of biochar and stabilization for seven weeks gave a higher CEC values compare with that of the parent soil (Table 1), and the CEC values increases gradually with increase in biochar application rates, $20 \%$ having the highest CEC value of (51.44). This could be attributed to the inherent characteristic of biochar. Biochar has high surface area, highly porous, variable charge organic matter that has the potential to increase soil CEC and surface sorption capacity when added to soil and thus increase the exchangeable base (Glaser et al, 2002; Lehman et al., 2003). The higher cation adsorption capacity of biochar may be attributed to the high surface negative charge resulting from oxidation of functional groups, mainly carboxylic and phenolic on the outer surface area of the biochar (Liang et al., 2006), Cheng et al., 2006 and 2008), showed that CEC values increase with time of incubation or stabilization as the biochar ages in the presence of $\mathrm{O}_{2}$ and $\mathrm{H}_{2} \mathrm{O}$ and possibly lead to the formation of stable biochar-trace element complexes in soil. The sand fraction forms the predominant fraction in terms of particle size Distribution for the parent soil sample $(0 \%)$, with a value of $(82.3 \%)$, with low clay $(11.90 \%)$, low Silt $(5.80 \%)$ total carbon $(0.24)$, so they tend to be permeable and suggesting low accumulation of plant material and high level of automobile waste.

The metals ( $\mathrm{Pb}, \mathrm{Cu}, \mathrm{Zn}, \mathrm{Cr}$ and $\mathrm{Cd})$ gradually decrease in concentration as the biochar increases $5 \%>10 \%>15 \%>20 \%$ (Fig 1). These metals seem to be adsorbed to biochar particle by surface complexation reaction leading to reduce concentration (Liang et al., 2006). All the heavy metals were within the permissible limit of Canada and India except for $\mathrm{Cr}$ which exceeded the permissible limit of India standards (Awashti, 2000).

Conversion of exchangeable form of heavy metals to less-available organic-bound metals via complexation reactions has been attributed as the reason for the significant reduction in extractable heavy metals in biochar amended soil (Brown et al., 2005; Farfel et al., 2005; Pichtel and Bradway 2008), thus binding of

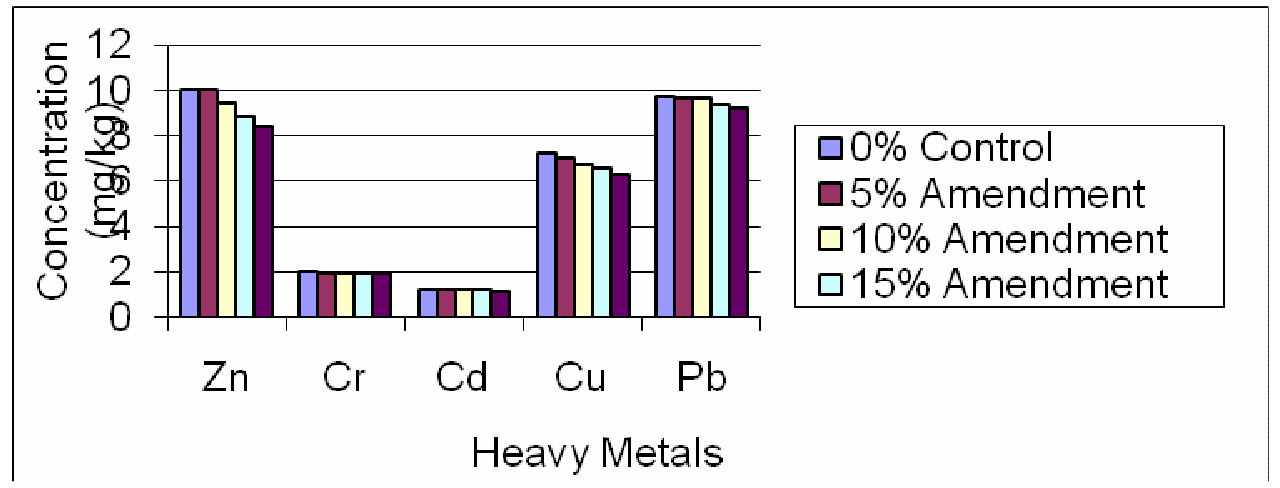

Figure 1: Levels of Heavy Metals in Parent and Amended Soils 
heavy metal in these fractions may reduce $\mathrm{Pb}, \mathrm{Cu}, \mathrm{Zn}, \mathrm{Cr}$ and $\mathrm{Cd}$ in the exchangeable fraction resulting in decrease in its bioavailability and mobility. In this study the Fractionation results indicate that soil amended with biochar show lower exchangeable and carbonate fraction for $\mathrm{Pb}, \mathrm{Cu}, \mathrm{Zn}, \mathrm{Cr}$ and $\mathrm{Cd}$, as the biochar application rate increases with $20 \%$ having the lowest concentration.

The highest concentration of the metal bound to exchangeable and carbonate phase was observed for $\mathrm{Pb}\left(1.79 \mathrm{mgkg}^{-1}\right)$ and $\mathrm{Zn}\left(1.70 \mathrm{mgkg}^{-1}\right)$ at $0 \%$ soil without biochar. Accumulation of $\mathrm{Zn}$ and $\mathrm{Pb}$ could be as a result of waste from battery charger dumpsites.

The results in Fig 2 show that Lead in the battery charger workshop soil are concentrated in the last three fractions. The majority of Lead in the soil and soil amended with biochar was associated with the residual fraction, having the range from $(0 \%) 2.11$ to $(20 \%) 2.42$. The residual fraction is considered the most stable, less reactive and less bioavailable since it is occluded within the crystal lattice layer of silicates and well crystallized oxide minerals (Segarra et al., 2008).

The organic and Fe-Mn Oxide fraction could be considered relatively stable, slowly mobile and poorly available but could change with variations in redox conditions (Horsfall and Spiff, 2005). The carbonate have been implicated as immobilizing most heavy metals by providing an adsorbing or nucleating surface and by buffering the soil $\mathrm{pH}$, They are only stable in soils with high $\mathrm{pH}$, thus $20 \%$ (1.42) biochar application is more stable and lower in concentration than $0 \%(2.11)$ which is the higher and more liable.

The exchangeable fraction which is the mobile and bioavailable fraction for plants uptakes gave the result of $1.32(20 \%)$ and $1.79(0 \%)$. This fraction represents heavy metals soluble in water as well as those held by electrostatic adsorption. The amount of metal in this phase indicated the environmental conditions of the soil. The high concentration of lead in this fraction suggests a greater contamination risk for lead (Wangboje et al., 2014). Copper content was observed to be greater in residual fraction followed by organic bound fraction, Fe - Mn oxide fraction, carbonate fraction and exchangeable (Fig 3). The exchangeable fraction of copper shows a much higher concentration at $0 \%$ than $20 \%$. The high concentration of Copper in this fraction also suggests a greater contamination risk for copper (Wangboje et al., 2014).

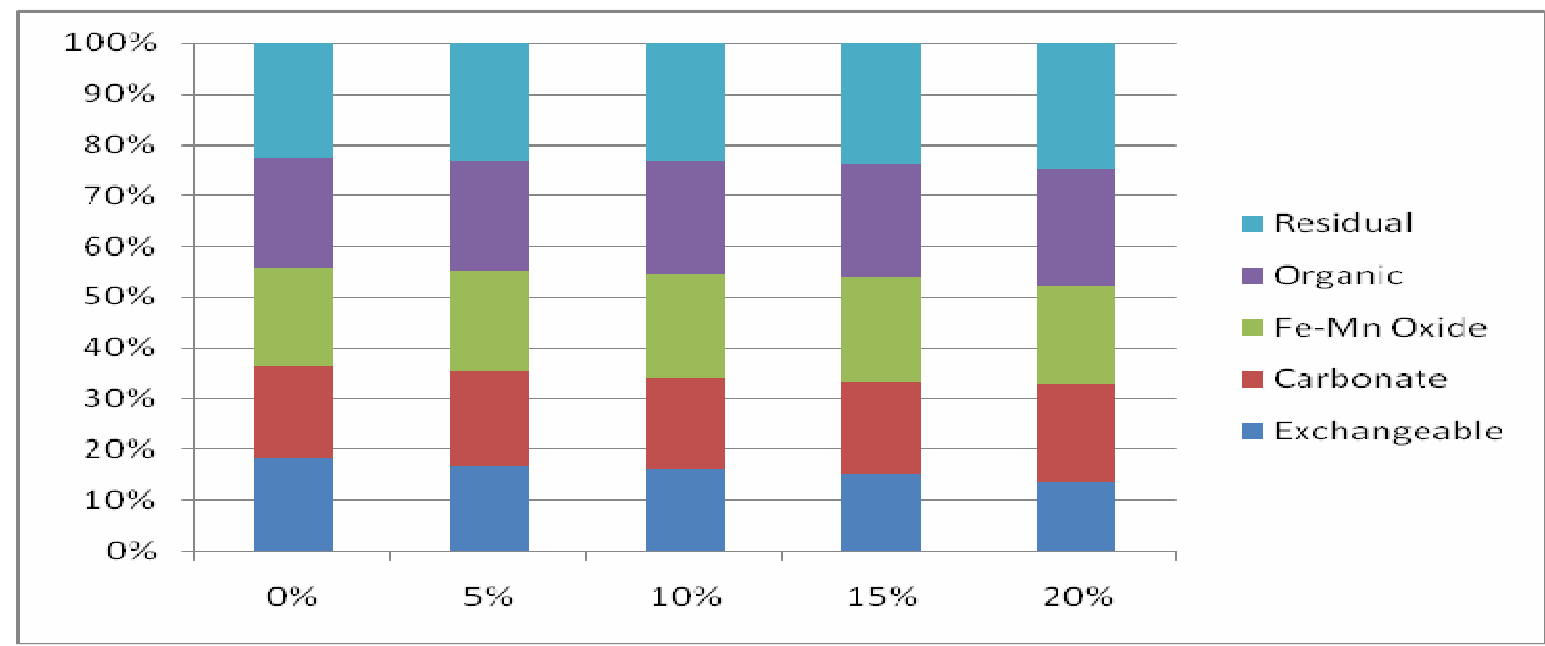

Figure 2: Percentage of $\mathrm{Pb}$ in the Various Geochemical Phases as a Function of $\mathrm{Pb}$ Content of Parent and Amended Soils

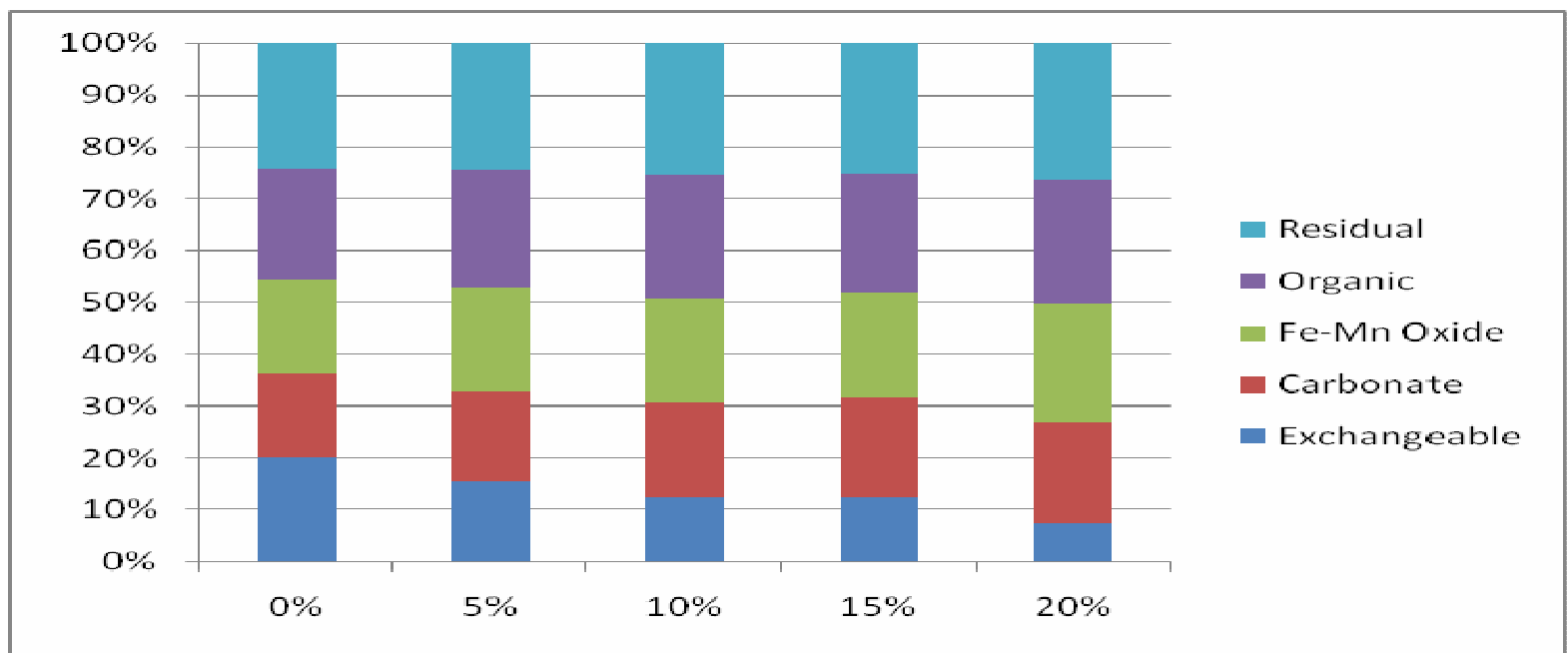

Figure 3: Percentage of $\mathrm{Cu}$ in the Various Geochemical Phases as a Function of $\mathrm{Cu}$ Content of Parent and Amended Soils 
The largest portion of zinc which were found in the residual fraction (2.33-2.66\%), metals bound to exchangeable, carbonate, Fe-Mn oxide and organic fraction were in the range of $0.62-1.70,1.06-1.69,1.11-1.72$, $2.25-2.66 \%$ respectively. The exchangeable fraction of zinc shows a much higher concentration at $0 \%$ than $20 \%$ (Fig 4). The high concentration of zinc in this fraction pose serious environmental problem to the underground water (Wangboje et al., 2014).

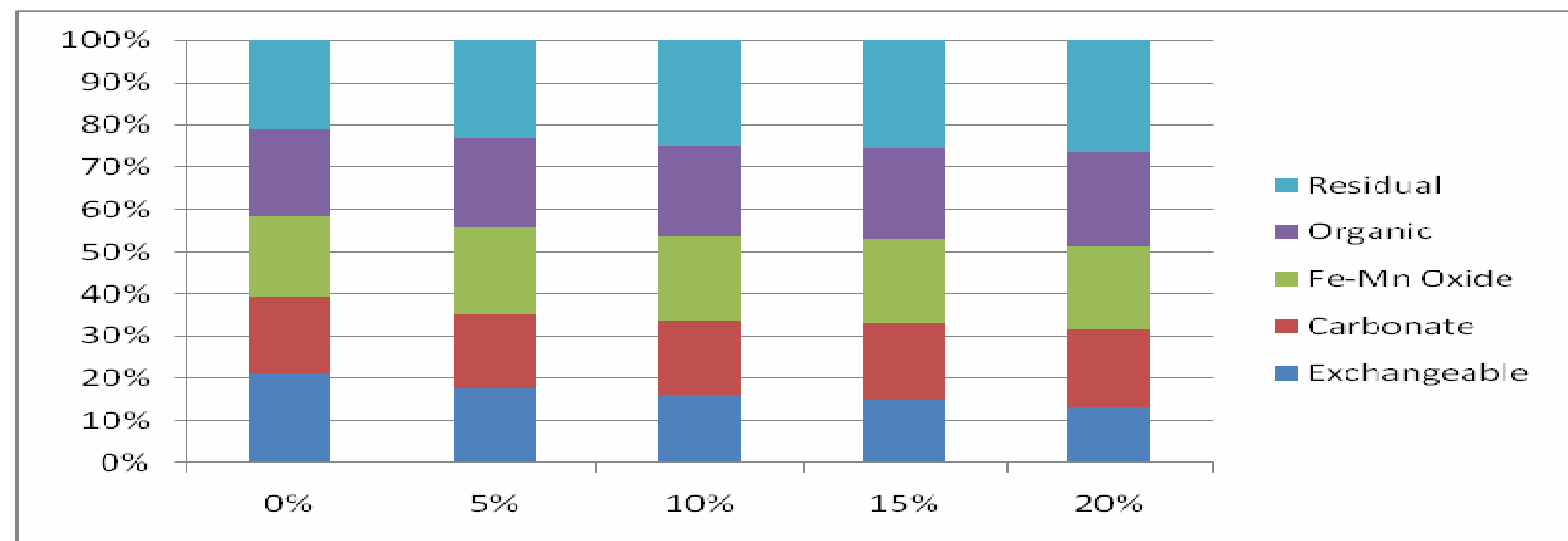

Figure 4: Percentage of Zn in the Various Geochemical Phases as a Function of Zn Content of Parent and Amended Soils

Although the concentration of cadmium in this study is low, accumulation of it could be hazardous. The association was seen to be in the order residual>organic $>$ Fe-Mn Oxide> carbonate>exchangeable (Fig. 5).

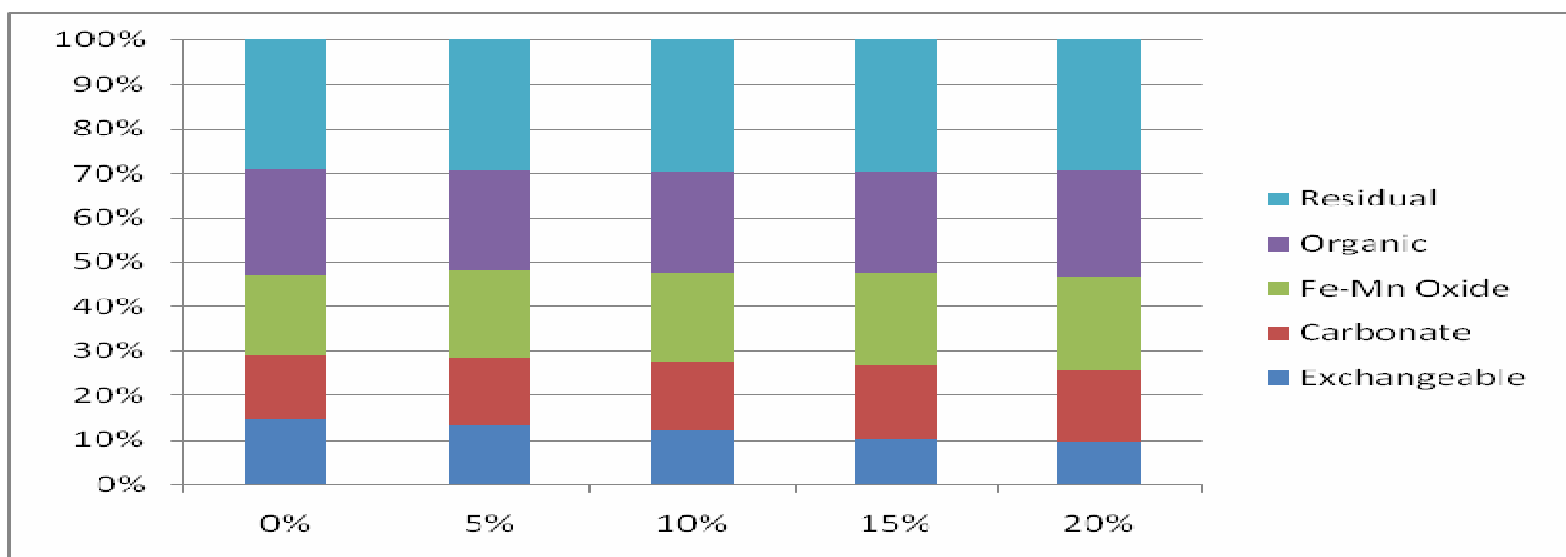

Figure 5: Percentage of Cd in the Various Geochemical Phases as a Function of Cd Content of Parent and Amended Soils

Chromium in the soil was mainly found in the residual fraction, (0.49-0.60). About 0.27-0.33, 0.45-0.48 and $0.33-0.39 \%$ was bound to carbonate, Fe-Mn oxide, and organic respectively. While a low range of $0.20-$ $0.26 \%$ was bound to exchangeable.

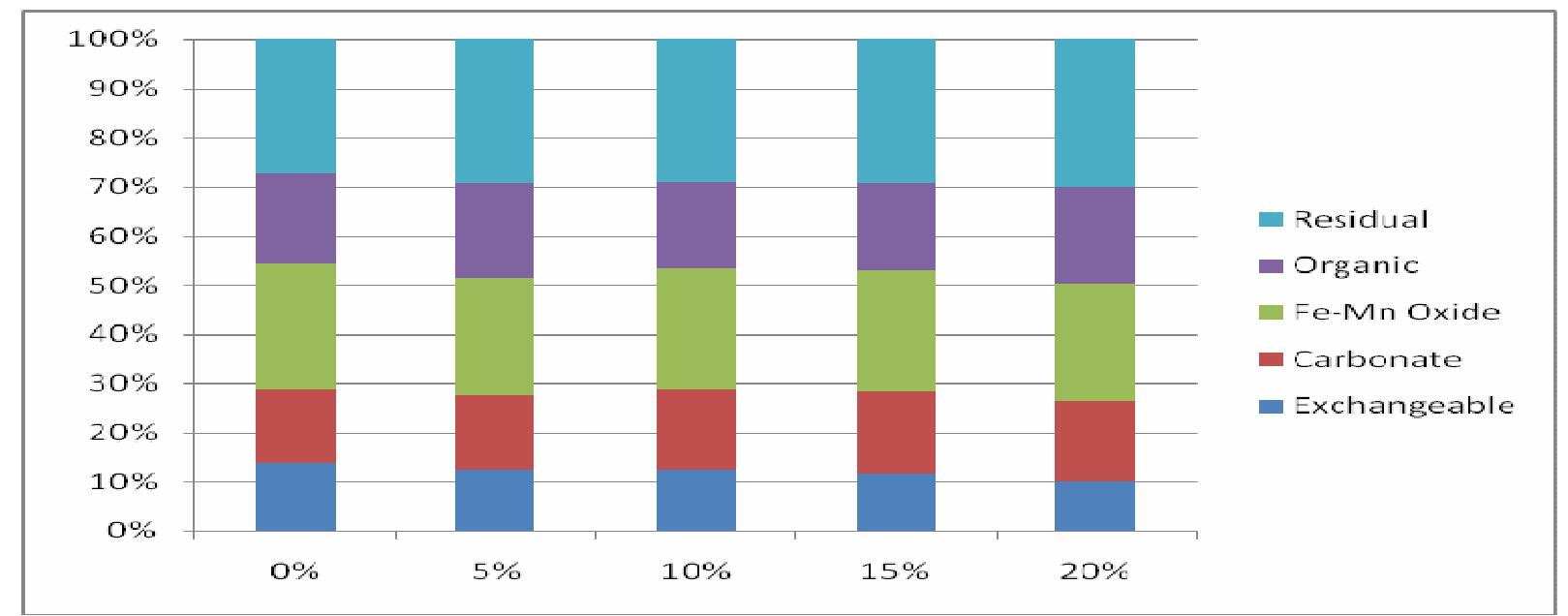

Figure 6: Percentage of $\mathrm{Cr}$ in the Various Geochemical Phases as a Function of Cr Content of Parent and Amended Soils. 
The relative index of metal mobility was calculated as a mobility factor (MF) on the basis of the following equation.

$$
M F=\frac{F 1+F 2 \times 100}{F 1+F 2+F 3+F 4+F 5}
$$

A high Mobility Factor value for heavy metals in soil has been interpreted as evidence of relatively high lability and biological availability (Ma and Rao 1997; Kabala and Singh 2001). In general the mobility factor was higher for all metals in the parent soil than the biochar amended soil (Table 2). This indicates a greater bioavailability and mobility and also shows formation of stable biochar-trace element complexes in soil.

Table 2: Mobility Factor for Metals in Parent and Amended soils

\begin{tabular}{llcccc}
\hline Levels of Biochar amendment & Zn & Cr & Cd & Cu & Pb \\
\hline $\mathbf{0 \%}$ & 36 & 29 & 29 & 37 & 37 \\
$5 \%$ & 27 & 28 & 29 & 33 & 35 \\
$10 \%$ & 27 & 29 & 28 & 31 & 34 \\
$15 \%$ & 26 & 29 & 27 & 32 & 33 \\
$20 \%$ & 21 & 28 & 26 & 27 & 32
\end{tabular}

The Environmental risk factor (ERF) was use to determine environmental risk in order to establish potential threat of heavy metals (Saenz, et al., 2003). The ERF was calculated using the formula; $\mathrm{ERF}=\mathrm{CSQV}-\mathrm{Ci} / \mathrm{CSQV}$

Where $\mathrm{CSQV}=$ Concentration of sediment quality value (heavy metal concentration in residual fraction of sediment which is equivalent to the background/pre-industrial concentration).

$\mathrm{Ci}=$ heavy metal concentration in the first four fractions of sediment. $(\mathrm{ERF}<0)$

From the result (Table 3) the heavy metals in the parent soil pose a potential threat to the environment

The contamination factor (CF) was calculated as:

$\mathrm{CF}=$ Metal concentration in sediment/Background concentration of metal in sediment (Lin et al., 2009). - -- - - - - - - - - - - - - - - - - - (3)

Since the contamination factor (CF) values exceeded unity (Table 3), the parent soil is clearly contaminated with these metals.

Table 3: Contamination Factor (CF) and Environmental Risk Factor (ERF) for Heavy Metals in the Parent soil

\begin{tabular}{ccc}
\hline Heavy metals & Contamination factor (CF) & Environmental risk factor (ERF) \\
\hline $\mathrm{Pb}$ & 3.53 & -1.42 \\
$\mathrm{Cu}$ & 3.08 & -1.38 \\
$\mathrm{Zn}$ & 3.08 & -0.75 \\
$\mathrm{Cd}$ & 2.44 & -2.12 \\
$\mathrm{Cr}$ & 2.69 & -2.20
\end{tabular}

Key: $\quad 1<\mathrm{CF}<3$ = Moderate contamination (Cd, $\mathrm{Cr}$ )

$3<\mathrm{CF}<6=$ Considerable contamination $(\mathrm{Pb}, \mathrm{Cu}, \mathrm{Pb})$

\section{CONCLUSION}

The results obtained in this study revealed that the soil from lead-acid battery workshop is moderately contaminated with $\mathrm{Cd}$ and $\mathrm{Cr}$, considerably contaminated with $\mathrm{Pb}, \mathrm{Cu}$ and $\mathrm{Zn}$. Addition of biochar increases soil $\mathrm{pH}$, organic carbon, total nitrogen, available phosphorus and CEC of the soil from lead-acid battery workshop. The presence of plant nutrients and ash in the biochar and also high surface area, porous nature and the capacity of biochar to act as a medium for microorganism are identified as the main reasons for the increase in soil

\section{REFERENCES}

Abeh, T., Gungshik, J., Adamu, M.M. (2007): Speciation Studies of Trace Elements Levels in Sediments from Zaramagada Stream in properties. The palm kernel shell biochar show a high sorption capacity of the heavy metals studied and it increases at the highest level of biochar treatment (20\%). There was an increase in the fractionation studies in reducible, oxidisable and residual fraction in all the metals. This trend indicates that the distribution of the metals in biochar amended soil is gradually shifting from the more labile fractions to the more stable fraction. Therefore application of biochar can be used to remediate soil and improve soil fertility from a contaminated or highly polluted soil.

Jos, Plateau State, Journal of Chemical Society of Nigeria. 32(2) 218-225

Arocena, J.M. and C. Opio, (2003): Prescribed FireInduced Changes in Properties of Sub-Boreal Forest Soils. Geoderma, 113: 1-16. 
Awashthi, S.K. (2000): Prevention of Food Adulteration Act no 37 of 1954. Central and State Rules as Amended for 1999, third ed. Ashoka Law House, New Delhi.

Banjoko, A. and Sobulo, R. A. (1994): Particle size distribution of $\mathrm{Fe}, \mathrm{Mn}, \mathrm{Zn}, \mathrm{Cu}$ and $\mathrm{B}$ in some Nigerian Soils. Nigeria Journal of Science 34: $60-163$.

Black, G.R. (1965): Particle Density. Methods of Soil Analysis, Part 1. In: C.A. Black (ed)American Society of Agronomy Monograph, No. 9

Bouyoucos, G.J. (1962): Hydrometer Method Improved for Making Particle-Size Analyses of Soils. Agronomy Journal. 54:464-465.

Bray, R.M. and Kurtz, L.T. (1947): Determination of Total Organic and Avaiiable form of Phosphorus in Soil. Soil Science 56: 39-45.

Brown, S., Christensen, B., Lombi, E., McLaughlin, M., McGrath, S., Colpaert, J. and Vangronsveld, J. (2005): An inter-laboratory study to test the ability of amendments to reduce the availability of $\mathrm{Cd}, \mathrm{Pb}$, and $\mathrm{Zn}$ in situ. Environmental Pollution 138: 34-45.

Cheng, C. H., Lehmann, J. and Engelhard, M. (2008): Natural oxidation of black carbon in soils: changes in molecular form and surface charge along a climosequence. Geochimica et Cosmochimica Acta 72: 1598-1610.

Cheng, C.H., Lehmann, J., Thies, J., Burton, S.D. and Engelhard, M.H. (2006): Oxidation of black carbon by biotic and abiotic processes. Organic Geochemistry 37: 1477-1488.

Farfel, M., Orlova, A., Chancy, R., Lees, P., Rohde, C, and Ashley P. (2005): Biosolids compost amendment for reducing soil lead hazards: a pilot study of organic amendment and grass seeding in urban yards. The Science of the Total Environment 340: 81-95.

Glaser, B., Lehmann, J., Zech, W. (2002): Ameliorating physical and chemical properties of highly weathered soils in the tropics with charcoal: a review. Biology and Fertility of Soils 35: 219-230.

Horsfall, M. (Jnr.), and Spiff, A. (2005): Speciation and bioavailability of heavy metals in sediment of Diobu River, Port Harcourt, Nigeria. European Journal of Science Reserve. 6(3): 20-36.

Igwe, J. C., Nnorom, I. C. and Gbaruko, B. C. (2005): Kinetics of radionuclides and heavy metals behaviour in soils: Implications for plant growth. African Journal of Biotechnology. 4(13): 1541 - 1547.

Joseph, S., Peacock, C., Lehmann, J. and Munroe, P. (2009): Developing a Biochar Classification and Test Methods. In: Biochar for Environmental Management: Science and Technology (Eds. Lehmann, J. \& Joseph, S.), Earthscan. Pp17

Kabala, C. and Singh, B. R. (2001): Fractionationand Mobility of Copper, lead, and zinc in Soil Profile in the vicinity of a Copper Smelter, Journal of Environmental Quality. 30:485495.

Lehmann, J., (2007a): A Handful of Carbon. Nature 447: $143-144$
Lehmann, J., (2007b): Bio-Energy In The Black. Frontiers in Ecology and the Environment 5: 381-387.

Lehmann, J., Kern, D. C., Glaser, B. and Woods, W. I., (2003): Amazonian Dark Earths: Origin, Properties And Management. Kluwer Academic Publishers, The Netherlands.

Liang, B., Lehmann, J., Solomon, D., Kinyangi, J., Grossman, J., O'Neill, B., Skjemstad, J.O., Thies, J., Luizao, F.J., Peterson, J., Neves, E.G., (2006): Black carbon increases cation exchange capacity in soils. Soil Science Society of American Journal. 70:1719-1730

Lin, J., Cai, M., Qi, A. and Hu, H. (2009): Contamination level and Speciation of Heavy Metals in Sediments from Yundang Lake, Xiamen. ICECS Second International Conference on Environmental and Computer Science, 28-30 December, Pp 48-52

Ma, L.Q. and Rao, G.N. (1997): Chemical fractionation of cadmium, copper, nickel, and zinc in contaminated soils. Journal of Environmental Quality, 26: 259-264.

Major, J., Steiner, C. and Downie, A. (2009): Biochar effects on nutrient leaching. In Biochar for Environmental Management, Science and Technology; Lehmann, J. Joseph, S., Eds. Earthscan, Ltd. London pp 271-284.

Novak, J.M., Busscher, W.J., Laird, D.L., Ahmedna, M., Watts, D.W. and Niandou, M.A.S. (2009): Impact of biochar amendment on fertility of a southeastern coastal plain soil. Soil Science 174: $105-112$.

Pichtel, J. and Bradway, D.J. (2008): Conventional crops and organic amendments for $\mathrm{Pb}, \mathrm{Cd}$ and $\mathrm{Zn}$ treatment at a severely contaminated site. Bioresource Technology 99: 1242-1251.

Pietikainen, J., Kiikkila, O. and Fritze, H. (2000): Charcoal as a habitat for microbes and its effect on the microbial community of the underlying humus. Oikos 89: 231-242.

Saenz, M., Blasco, J. and Gomez-Parra, A. (2003): Speciation of heavy metals in sediments of three coastal ecosystems in the Gulf of Cadiz, southwest Iberian peninsula. Environmental Toxicology and Chemistry 22 (12): 33-39.

Sanders, J. E., (1982): The Effect of pH upon the Cu and cupric ion concentrations in soil solution. Jornal Soil Science. 33: 679 - 689.

Segarra, M.J.B., Prego, R., Wilson, M.J. Bacon, J. and Santos-Echeandia, J. S. (2008): Metal speciation in surface sediments of the Vigo Ria (N.W. Iberian Peninsula) Science Marjor. 72(1): 119-126

Solomon, D.J., Lehmann, J., Thies, T., Schafer, B., Liang, J., Kinyangi, E., Neves, J., Petersen, F., Luizo and J. Skjemstad, (2007): Molecular Signature and Sources of Biochemical recalcitrance of organic $\mathrm{C}$ in Amazonian dark earths. Geochimica et cosmochimica Acta, 71: 2285-2298.

Tessier, A. Campbell, G.C. and Bisson, M. (1979): Sequential extraction procedures for the speciation of particulate trace metals. Journal Analytical chemistry, 51 (7): 844-851 
Udosen, E. D., Benson, N. U., Essien, J. P. and Ebong, G. A. (2006): Relation between Aqua-regia. Extractable Heavy metals in soils and Manihot utilssima within amunicipal dumpsite. International Journal of Soil Sciences 1 (1); 27 - 32 .

Verheijen, F., Jeffery S., Bastos A.C., Van der Velde, M., Diafas, I. (2010): Biochar Application to Soils: A Critical Scientific Review of Effects of Soil Properties, Processes and Functions. JRC Scientific and Technical Reports, EUR 24099 - EN, Italy

Vogel's, (2008): text book of quantitative chemical analysis. $6^{\text {th }}$ Ediction, Prentice Hall, England, pp277.

Walkey, A. and Black, I.A . (1934): An Examination of the digestion method for the determination of soil organic matter and a proposed chromic acid titration. Soil Science, 37: 2938.
Wangboje, O.M., Oronsaye, J.A.O., Okieimen, F.E. and Oguzie, F.A. (2014): Chemical Fractionation of Heavy Metals in the Sediments of the Ikpoba Reservoir, Benin City Nigeria. Nigeria journal of applied science. 32: 241-254.

Warnock, D.D., Lehmann, J. and Kuyper, T. W. (2007): Mycorrhizal response to biochar in soil-Concept and mechanisms. Plant Soil, 300: 9-20.

Yamato, M., Okimori, Y., Wibowo, I.F., Anshori, S. and Ogawa, M. (2006): Effects of the application of charred bark in Acacia mangium on the yield of maize, cowpea, peanut and soil chemical properties in south Sumatra, Indonesia. Soil Science Plant Nutrition 52:489-495. 